ГЕОЭКОЛОГИЯ

УДК 556.04

ISSN 1609-0683

DOI: https://doi.org/10.17308/geo.2020.3/3026

\title{
Геоэкологическая характеристика участка реки Малка от города Прохладный до устья
}

\author{
С. И. Шагин, М. А. Шамарина ${ }^{凶}$, Н. В. Татаренко \\ Кабардино-Балкарский государственный университет им. Х. М. Бербекова, Российская Федерация \\ (360004, г. Нальчик, ул. Чернышевского, 173)
}

\begin{abstract}
Аннотация: Цель: изучить многообразие проявления русловых и пойменных процессов в дельте реки Малка и оценить их воздействие на экосистему, на основе анализа данных из открытых источников и собственных наблюдений составить комплексную характеристику реки Малка, определить ее гидрохимическую характеристику и описать ионно-солевой состав, изучить современное экологическое и физико-географическое состояние экосистемы в районе г. Прохладный. Методыl: при выполнении исследования использованы общегеографические методы, а также общепринятые геоботанические и почвенные методы. Полевые гидрометрические работы включали: измерение ширины, глубины, скорости течения, уклона реки. Результаты: осуществлены полевые гидрометрические работы. Определены основные гидрологические и гидрометрические характеристики реки на исследуемом участке. Исследован химический состав аллювиальных отложений на территории исследуемого участка реки. Обнаружено содержание в грунте оксидов железа, титана и алюминия. Исследован химически состав и качество воды реки Малка Установлено, что анализируемая вода соответствует третьему классу качества - умеренно загрязненная. Bblводы: В период с 2015 по 2019 годы изучено: физико-географическое состояние участка реки Малка от города Прохладный до устья; состояние экосистемы; процессы изменения содержания водорастворимых солей в почвах под воздействием природных и антропогенных факторов. На основании анализа имеющихся литературных данных и собственных наблюдений установлено, что формирование русловых форм рельефа происходит медленно, под влиянием множества факторов, самыми значимыми из которых являются изменения климата, почв и эволюция самой реки.
\end{abstract}

Ключевые слова: гидрологический режим, морфометрические показатели, экосистема, пойменные ландшафты, химический состав.

Для циитирования: Шагин С. И., Шамарина М. А., Татаренко Н. В. Геоэкологическая характеристика участка реки Малка от города Прохладный до устья // Вестник Воронежского государственного университета. Серия География. Геоэкология, 2020, № 3, c. 72-77. DOI: https://doi.org/10.17308/geo.2020.3/3026

\section{ВВЕДЕНИЕ}

Состояние наземных экосистем и природных биокомплексов в поймах дельт рек существенно зависит от их гидрологического режима [5]. Возросшее со второй половины XX века антропогенное воздействие на пойменную экосистему реки Малка заметно изменило ее геоэкологическое состояние. Современные данные по переувлажнению земель, приуроченных к долине реки Малка отсут- ствуют в связи с тем, что в последние 30 лет мониторинговые работы на этой территории не проводились [4]. Тенденции развития негативных процессов и явлений, связанных с возросшим антропогенным воздействием, делают необходимым проведение исследований и разработку мероприятий, направленных на рациональное природопользование и устойчивое функционирование экосистемы реки.

() Шагин С.И., Шамарина М.А., Татаренко Н.В., 2020

$₫$ Шамарина Марина Анатольевна, e-mail: shamarinam@mail.ru

Контент доступен под лицензией Creative Commons Attribution 4.0 License. 
Термический режим пойменного участка реки Малка (температура воздуха, ${ }^{\circ} \mathrm{C}$ )

[Table 1. Thermal regime of the Malka river floodplain (air temperature, ${ }^{\circ} \mathrm{C}$ )]

\begin{tabular}{|c|c|c|c|c|c|c|c|c|c|c|c|c|}
\hline \multirow{2}{*}{$\begin{array}{l}\text { Год/ } \\
\text { Year }\end{array}$} & \multicolumn{2}{|c|}{$\begin{array}{c}\text { Январь/ } \\
\text { January }\end{array}$} & \multicolumn{2}{|c|}{$\begin{array}{l}\text { Февраль/ } \\
\text { February }\end{array}$} & \multicolumn{2}{|c|}{ Март/ March } & \multicolumn{2}{|c|}{ Апрель/ April } & \multicolumn{2}{|c|}{ Май/ Мау } & \multicolumn{2}{|c|}{ Июнь/ June } \\
\hline & $\begin{array}{c}\text { День/ } \\
\text { Day }\end{array}$ & $\begin{array}{l}\text { Ночь/ } \\
\text { Night }\end{array}$ & $\begin{array}{c}\text { День/ } \\
\text { Day }\end{array}$ & $\begin{array}{l}\text { Ночь/ } \\
\text { Night }\end{array}$ & $\begin{array}{l}\text { День/ } \\
\text { Day }\end{array}$ & $\begin{array}{l}\text { Ночь/ } \\
\text { Night }\end{array}$ & $\begin{array}{c}\text { День/ } \\
\text { Day }\end{array}$ & $\begin{array}{l}\text { Ночь/ } \\
\text { Night }\end{array}$ & $\begin{array}{l}\text { День/ } \\
\text { Day }\end{array}$ & $\begin{array}{l}\text { Ночь/ } \\
\text { Night }\end{array}$ & $\begin{array}{c}\text { День/ } \\
\text { Day }\end{array}$ & $\begin{array}{l}\text { Ночь/ } \\
\text { Night }\end{array}$ \\
\hline 2015 & 2,4 & 2,5 & 3,9 & 2,3 & 8,2 & 4,5 & 14,6 & 9,8 & 23,0 & 16,0 & 28,6 & 22,6 \\
\hline 2016 & 3,5 & 2,4 & 4,5 & 1,5 & 9,5 & 5,1 & 16,2 & 6,3 & 25,0 & 14,0 & 26,2 & 23,5 \\
\hline 2017 & 4,5 & 2,9 & 4,6 & 2,5 & 10,2 & 8,2 & 18,9 & 7,6 & 24,3 & 12,3 & 27,3 & 24,8 \\
\hline 2018 & 6,2 & 3,5 & 5,5 & 3,6 & 11,2 & 9,1 & 20,1 & 8,4 & 25,3 & 14,9 & 28,3 & 14,8 \\
\hline \multirow[t]{3}{*}{2019} & 7,2 & 4,3 & 7,3 & 5,2 & 12,3 & 5,2 & 16,3 & 5,4 & 26,8 & 18,2 & 25,4 & 22,1 \\
\hline & \multicolumn{2}{|c|}{ Июль/ July } & \multicolumn{2}{|c|}{$\begin{array}{c}\text { Август/ } \\
\text { August }\end{array}$} & \multicolumn{2}{|c|}{$\begin{array}{l}\text { Сентябрь/ } \\
\text { September }\end{array}$} & \multicolumn{2}{|c|}{$\begin{array}{l}\text { Октябрь/ } \\
\text { October }\end{array}$} & \multicolumn{2}{|c|}{$\begin{array}{c}\text { Ноябрь/ } \\
\text { November }\end{array}$} & \multicolumn{2}{|c|}{$\begin{array}{l}\text { Декабрь/ } \\
\text { December }\end{array}$} \\
\hline & $\begin{array}{l}\text { День/ } \\
\text { Day }\end{array}$ & $\begin{array}{l}\text { Ночь/ } \\
\text { Night }\end{array}$ & $\begin{array}{c}\text { День/ } \\
\text { Day }\end{array}$ & $\begin{array}{l}\text { Ночь/ } \\
\text { Night }\end{array}$ & $\begin{array}{l}\text { День/ } \\
\text { Day }\end{array}$ & $\begin{array}{l}\text { Ночь/ } \\
\text { Night }\end{array}$ & $\begin{array}{c}\text { День/ } \\
\text { Day }\end{array}$ & $\begin{array}{l}\text { Ночь/ } \\
\text { Night }\end{array}$ & $\begin{array}{l}\text { День/ } \\
\text { Day }\end{array}$ & $\begin{array}{l}\text { Ночь/ } \\
\text { Night }\end{array}$ & $\begin{array}{l}\text { День/ } \\
\text { Day }\end{array}$ & $\begin{array}{l}\text { Ночь/ } \\
\text { Night }\end{array}$ \\
\hline 2015 & 31,1 & 24,7 & 31,6 & 23,5 & 28,0 & 21,0 & 14,5 & 18,5 & 10,4 & 4,6 & $-4,3$ & $-2,1$ \\
\hline 2016 & 34,8 & 24,3 & 36,2 & 25,0 & 26,5 & 22,1 & 15,2 & 14,3 & 11,2 & $-3,6$ & $-5,3$ & $-1,5$ \\
\hline 2017 & 32,5 & 25,3 & 32,1 & 24,7 & 25,4 & 23,8 & 16,8 & 12,8 & 10,8 & 4,8 & 7,3 & $-1,3$ \\
\hline 2018 & 34,5 & 25,1 & 24,3 & 26,2 & 27,3 & 20,3 & 14,8 & 15,3 & 9,8 & 7,2 & $-2,5$ & $-7,0$ \\
\hline 2019 & 36,7 & 22,3 & 32,4 & 30,1 & 23,1 & 19,4 & 20,1 & 12,5 & 12,1 & 5,2 & $-3,5$ & $-4,2$ \\
\hline
\end{tabular}

Таблица 2

Барический режим пойменного участка реки Малка (давление в мм. рт. ст.)

[Table 2. Baric regime of the floodplain section of the Malka River (pressure in $\mathrm{mm} \mathrm{Hg}$ )]

\begin{tabular}{|c|c|c|c|c|c|c|c|c|c|c|c|c|}
\hline \multirow{2}{*}{$\begin{array}{l}\text { Год/ } \\
\text { Year }\end{array}$} & \multicolumn{2}{|c|}{$\begin{array}{c}\text { Январь/ } \\
\text { January }\end{array}$} & \multicolumn{2}{|c|}{$\begin{array}{l}\text { Февраль/ } \\
\text { February }\end{array}$} & \multicolumn{2}{|c|}{ Март/ March } & \multicolumn{2}{|c|}{ Апрель/ April } & \multicolumn{2}{|c|}{ Май/ Мау } & \multicolumn{2}{|c|}{ Июнь/ June } \\
\hline & $\begin{array}{c}\text { День/ } \\
\text { Day }\end{array}$ & $\begin{array}{l}\text { Ночь/ } \\
\text { Night }\end{array}$ & $\begin{array}{c}\text { День/ } \\
\text { Day }\end{array}$ & $\begin{array}{l}\text { Ночь/ } \\
\text { Night }\end{array}$ & $\begin{array}{c}\text { День/ } \\
\text { Day }\end{array}$ & $\begin{array}{l}\text { Ночь/ } \\
\text { Night }\end{array}$ & $\begin{array}{l}\text { День/ } \\
\text { Day }\end{array}$ & $\begin{array}{l}\text { Ночь/ } \\
\text { Night }\end{array}$ & $\begin{array}{c}\text { День/ } \\
\text { Day }\end{array}$ & $\begin{array}{l}\text { Ночь/ } \\
\text { Night }\end{array}$ & $\begin{array}{c}\text { День/ } \\
\text { Day }\end{array}$ & $\begin{array}{l}\text { Ночь/ } \\
\text { Night }\end{array}$ \\
\hline 2015 & 741 & 742 & 745 & 745 & 742 & 746 & 743 & 746 & 743 & 742 & 751 & 746 \\
\hline 2016 & 743 & 753 & 741 & 747 & 738 & 743 & 746 & 752 & 752 & 743 & 750 & 747 \\
\hline 2017 & 751 & 755 & 745 & 743 & 743 & 752 & 752 & 743 & 750 & 747 & 747 & 750 \\
\hline 2018 & 751 & 752 & 748 & 743 & 746 & 750 & 747 & 747 & 750 & 752 & 754 & 756 \\
\hline \multirow[t]{3}{*}{2019} & 746 & 749 & 749 & 746 & 752 & 752 & 749 & 755 & 755 & 745 & 754 & 759 \\
\hline & \multicolumn{2}{|c|}{ Июль/ July } & \multicolumn{2}{|c|}{$\begin{array}{c}\text { Август/ } \\
\text { August }\end{array}$} & \multicolumn{2}{|c|}{$\begin{array}{l}\text { Сентябрь/ } \\
\text { September }\end{array}$} & \multicolumn{2}{|c|}{$\begin{array}{c}\text { Октябрь/ } \\
\text { October }\end{array}$} & \multicolumn{2}{|c|}{$\begin{array}{c}\text { Ноябрь/ } \\
\text { November }\end{array}$} & \multicolumn{2}{|c|}{$\begin{array}{l}\text { Декабрь/ } \\
\text { December }\end{array}$} \\
\hline & $\begin{array}{c}\text { День/ } \\
\text { Day }\end{array}$ & $\begin{array}{l}\text { Ночь/ } \\
\text { Night }\end{array}$ & $\begin{array}{c}\text { День/ } \\
\text { Day }\end{array}$ & $\begin{array}{l}\text { Ночь/ } \\
\text { Night }\end{array}$ & $\begin{array}{c}\text { День/ } \\
\text { Day }\end{array}$ & $\begin{array}{l}\text { Ночь/ } \\
\text { Night }\end{array}$ & $\begin{array}{c}\text { День/ } \\
\text { Day }\end{array}$ & $\begin{array}{l}\text { Ночь/ } \\
\text { Night }\end{array}$ & $\begin{array}{c}\text { День/ } \\
\text { Day }\end{array}$ & $\begin{array}{l}\text { Ночь/ } \\
\text { Night }\end{array}$ & $\begin{array}{c}\text { День/ } \\
\text { Day }\end{array}$ & $\begin{array}{l}\text { Ночь/ } \\
\text { Night }\end{array}$ \\
\hline 2015 & 748 & 749 & 749 & 743 & 742 & 736 & 743 & 740 & 743 & 740 & 743 & 743 \\
\hline 2016 & 748 & 753 & 755 & 744 & 745 & 743 & 740 & 739 & 740 & 741 & 740 & 741 \\
\hline 2017 & 746 & 749 & 753 & 740 & 737 & 737 & 742 & 740 & 742 & 740 & 738 & 738 \\
\hline 2018 & 750 & 753 & 745 & 736 & 740 & 743 & 746 & 746 & 741 & 739 & 739 & 740 \\
\hline 2019 & 760 & 754 & 752 & 740 & 753 & 750 & 751 & 749 & 740 & 740 & 740 & 742 \\
\hline
\end{tabular}

\section{ОБЪЕКТЫ И МЕТОДЫ ИССЛЕДОВАНИЯ}

Объектом исследования нами выбрана пойма и дельта реки Малка на участке длиной 25 км, расположенном в юго-восточной части города Прохладный. При выполнении исследования использованы общегеографические методы, а также общепринятые геоботанические и почвенные методы. Полевые гидрометрические работы включали: измерение ширины, глубины, скорости течения, уклона реки [3]. Химический состав грунта и воды определялся в ЦКП «Рентгеновская диагностика материалов» Кабардино-Балкарского государственного университета им. Х. М. Бербекова на сертифицированном оборудовании.

\section{РЕЗУЛЬТАТЫ И ОБСУЖДЕНИЕ}

С использованием статистических данных [1] и по результатам собственных измерений в период с января 2015 по декабрь 2019 года для исследуемого участка реки Малка нами изучены термический режим (таблица 1), барический режим (таб- 
Средний показатель скорости ветра на пойменном участке реки Малка (скорость ветра в м/с)

[Table 3. Average wind speed in the Malka river floodplain (wind speed in $\mathrm{m} / \mathrm{s}$ )]

\begin{tabular}{|c|c|c|c|c|c|c|c|c|c|c|c|c|}
\hline \multirow{2}{*}{$\begin{array}{l}\text { Год/ } \\
\text { Year }\end{array}$} & \multicolumn{2}{|c|}{$\begin{array}{c}\text { Январь/ } \\
\text { January }\end{array}$} & \multicolumn{2}{|c|}{$\begin{array}{l}\text { Февраль/ } \\
\text { February }\end{array}$} & \multicolumn{2}{|c|}{ Март/ March } & \multicolumn{2}{|c|}{ Апрель/ April } & \multicolumn{2}{|c|}{ Май/ Мау } & \multicolumn{2}{|c|}{ Июнь/ June } \\
\hline & $\begin{array}{l}\text { День/ } \\
\text { Day }\end{array}$ & $\begin{array}{l}\text { Ночь/ } \\
\text { Night }\end{array}$ & $\begin{array}{l}\text { День/ } \\
\text { Day }\end{array}$ & $\begin{array}{l}\text { Ночь/ } \\
\text { Night }\end{array}$ & $\begin{array}{c}\text { День/ } \\
\text { Day }\end{array}$ & $\begin{array}{l}\text { Ночь/ } \\
\text { Night }\end{array}$ & $\begin{array}{l}\text { День/ } \\
\text { Day }\end{array}$ & $\begin{array}{l}\text { Ночь/ } \\
\text { Night }\end{array}$ & $\begin{array}{l}\text { День/ } \\
\text { Day }\end{array}$ & $\begin{array}{l}\text { Ночь/ } \\
\text { Night }\end{array}$ & $\begin{array}{l}\text { День/ } \\
\text { Day }\end{array}$ & $\begin{array}{l}\text { Ночь/ } \\
\text { Night }\end{array}$ \\
\hline 2015 & 1 & 1 & 2 & 3 & 1 & 1 & 2 & 3 & 2 & 2 & 2 & 2 \\
\hline 2016 & 2 & 4 & 8 & 4 & 1 & 2 & 5 & 2 & 5 & 2 & 4 & 5 \\
\hline 2017 & 4 & 5 & 4 & 2 & 7 & 3 & 5 & 7 & 1 & 5 & 5 & 7 \\
\hline \begin{tabular}{|l|}
2018 \\
\end{tabular} & 1 & 6 & 8 & 7 & 1 & 4 & 7 & 5 & 3 & 8 & 7 & 2 \\
\hline \multirow[t]{3}{*}{2019} & 2 & 5 & 3 & 8 & 7 & 4 & 1 & 2 & 3 & 5 & 5 & 6 \\
\hline & \multicolumn{2}{|c|}{ Июль/ July } & \multicolumn{2}{|c|}{$\begin{array}{c}\text { Август/ } \\
\text { August }\end{array}$} & \multicolumn{2}{|c|}{$\begin{array}{l}\text { Сентябрь/ } \\
\text { September }\end{array}$} & \multicolumn{2}{|c|}{$\begin{array}{l}\text { Октябрь/ } \\
\text { October }\end{array}$} & \multicolumn{2}{|c|}{$\begin{array}{l}\text { Ноябрь/ } \\
\text { November }\end{array}$} & \multicolumn{2}{|c|}{$\begin{array}{l}\text { Декабрь/ } \\
\text { December }\end{array}$} \\
\hline & $\begin{array}{l}\text { День/ } \\
\text { Day }\end{array}$ & $\begin{array}{l}\text { Ночь/ } \\
\text { Night }\end{array}$ & $\begin{array}{l}\text { День/ } \\
\text { Day }\end{array}$ & $\begin{array}{l}\text { Ночь/ } \\
\text { Night }\end{array}$ & $\begin{array}{l}\text { День/ } \\
\text { Day }\end{array}$ & $\begin{array}{l}\text { Ночь/ } \\
\text { Night }\end{array}$ & $\begin{array}{l}\text { День/ } \\
\text { Day }\end{array}$ & $\begin{array}{l}\text { Ночь/ } \\
\text { Night }\end{array}$ & $\begin{array}{l}\text { День/ } \\
\text { Day }\end{array}$ & $\begin{array}{l}\text { Ночь/ } \\
\text { Night }\end{array}$ & $\begin{array}{l}\text { День/ } \\
\text { Day }\end{array}$ & $\begin{array}{l}\text { Ночь/ } \\
\text { Night }\end{array}$ \\
\hline 2015 & 3 & 2 & 1 & 3 & 2 & 2 & 1 & 2 & 2 & 1 & 2 & 2 \\
\hline 2016 & 8 & 2 & 5 & 2 & $F$ & 1 & 5 & 5 & 8 & 7 & 2 & 5 \\
\hline 2017 & 2 & 3 & 5 & 5 & 4 & 5 & 2 & 1 & 1 & 5 & 5 & 8 \\
\hline 2018 & 2 & 5 & 7 & 5 & 7 & 4 & 1 & 4 & 5 & 2 & 4 & 8 \\
\hline 2019 & 4 & 10 & 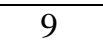 & 7 & 3 & 6 & 3 & 2 & 4 & 6 & 3 & 4 \\
\hline
\end{tabular}

лица 2), измерен средний показатель скорости ветра (таблица 3).

Годовой ход температуры воды на исследуемом участке характеризуется низкими значениями с ноября по март: она не превышает $(+2,5)-(+3,5)^{\circ} \mathrm{C}$, при минимальной в январе, $(+0,2)-(+0,4)^{\circ} \mathrm{C}$. Наиболее существенный рост температуры зафиксирован в апреле и мае на $(+2,5)-(+4,0)$ и на $(+1,5)$ $(+3,0)^{\circ} \mathrm{C}$, соответственно. В июне-августе температура воды повышается меньше, примерно, на $(+0,5)-(+1,5)^{\circ} \mathrm{C}$. Наиболее высокая температура воды отмечена в июле, в нижнем течении она достигала $(+13,6)-\left(+18,5^{\circ} \mathrm{C}\right)$.

Начиная с сентября, температура воды в реке понижается на $(+0,2)-\left(+1,5^{\circ} \mathrm{C}\right)$. С октября вода становится холоднее на $(+2,0)-(+3,5)^{\circ} \mathrm{C}$ в месяц.

Основные морфометрические показатели исследуемого участка реки Малка установлены следующим образом: коэффициент извилистости 1,6 ; уклон $-1,2 \%$; средняя ширина - 169 м; средняя площадь поперечного сечения $-78,0$ м² $^{2}$ расход воды - $117 \mathrm{~m}^{3}$.

Все разнообразие пойменных ландшафтов на исследуемом участке реки Малка неразрывно связано с русловыми процессами и эрозионно-аккумулятивной деятельностью водного потока в речном русле [4]. В низовье долина реки Малка расширяется, меандрирует. Дно участка сложено гравием с иловыми отложениями, русло однорукавное. Деформация берегов четко выраженная. Левый берег имеет более устойчивое состояние, чем правый, который более крутой и высотой до 2,5 м. На всем исследуемом участке насчитывается 21 меандра и 12 крупных островов.

Для исследования химического состава аллювиальных отложений в период межени 2016 года нами отобраны 8 образцов. Образцы № 1-4 - пробы ила взятые с острова, площадь которого составляет 22,797 м². Мощность образца № $1-35,2 \mathrm{cm;}$ № 2 - 41,50 см; № 3 - 44,5 см; № 4 - 42,5 см. Образец № 5 - песок, взят на участке фарватера в период межени; образец № 6 - береговой ил; образцы №7-8 - обломочный материал в русле реки. Элементный состав аллювиальных отложений представлен в таблице 4.

В результате анализа установлено, что химический состав аллювиальных наносов весьма разнообразен. Наиболее велико содержание оксида кремния (кремнезема). В составе присутствуют оксиды титана, железа, алюминия; соли кальция и калия.

Для исследования качества воды нами производился отбор образцов по стандартной методике [2]. Установлено, что гидрохимический состав воды реки Малка изменяется в зависимости от гидрологического режима и времени года. В период паводковых явлений, увеличивалась концентрация взвешенных веществ (1127-1294 мг/л), прозрачность воды уменьшалась до 0-1,8 см, а в межень физико-химические свойства водоема улучшались. Пробы воды на исследуемом участке показали слабощелочную реакцию $\mathrm{pH}=7,7$. Концент- 
Элементный состав образцов аллювиальных отложений (вес, \%)

[Table 4. Elemental composition of alluvial sediment samples (wt, \%)]

\begin{tabular}{|c|c|c|c|c|c|c|c|c|}
\hline Химический элемент / & \multicolumn{7}{|c|}{ № образца / Sample No. } \\
\cline { 2 - 9 } Chemical element & 1 & 2 & 3 & 4 & 5 & 6 & 7 & 8 \\
\hline $\mathrm{O}$ & 52,9 & 51,3 & 44,9 & 16,0 & 42,0 & 53,0 & 60,0 & 49,9 \\
\hline $\mathrm{Si}$ & 26,4 & 28,1 & 15,8 & 30,0 & 22,0 & 29,0 & 33,0 & 21,1 \\
\hline $\mathrm{Al}$ & 6,8 & 10,9 & 8,3 & 0 & 6,3 & 8,0 & 1,4 & 8,5 \\
\hline $\mathrm{Fe}$ & 5,0 & 0 & 22,2 & 0 & 11,0 & 2,5 & 0 & 1,3 \\
\hline $\mathrm{Ca}$ & 3,2 & 1,4 & 0,8 & 0 & 2,8 & 2,4 & 0 & 1,5 \\
\hline $\mathrm{K}$ & 2,7 & 1,5 & 0,5 & 0 & 9,2 & 1,5 & 0,6 & 4,2 \\
\hline $\mathrm{Na}$ & 1,3 & 6,9 & 0,7 & 0 & 1,6 & 2,0 & 0 & 4,7 \\
\hline $\mathrm{Mg}$ & 1,2 & 0 & 6,6 & 0 & 0,9 & 1,0 & 0 & 0 \\
\hline $\mathrm{Ti}$ & 0,4 & 0 & 0,7 & 0,2 & 2,0 & 6,4 & 15,0 & 0 \\
\hline $\mathrm{Mn}$ & 0 & 0 & 0,2 & 0 & 0 & 0 & 0 & 1,1 \\
\hline $\mathrm{W}$ & 0 & 0 & 0 & 0 & 0,2 & 0,1 & 0 & 0 \\
\hline $\mathrm{C}$ & 0 & 0 & 0 & 0 & 0 & 0 & 18,0 & 31,7 \\
\hline
\end{tabular}

рация нитратов и фосфатов во всех пробах не превышала допустимых значений. В составе исследуемых проб преобладали сульфатно-гидрокарбонатные ионы. Минерализация исследуемой воды - 378-507 мг/л. Вода жесткая - 5,0-6,6 мг экв/л.

Во всех взятых для анализа образцах содержались ионы металлов. Наибольшее значение их приходилось на паводковый период и составляло, в среднем 3,6-4,6 ПДК железа (0,01 мг/л) и 4-5 ПДК меди (0,01 мг/л). Обнаружена повышенная концентрация молибдена до 10 ПДК (0,001 мг/л). Исследуемая вода соответствовала третьему классу качества (умеренно загрязненная).

Важнейшая роль в формировании и преобразовании почв, рельефа, водного режима и микроклимата принадлежит растительности. На исследуемом участке наиболее благоприятные условия для произрастания трав и кустарников. Пойменный лес, приуроченный к прирусловой части, выполняет защитные функции, скрепляет корневыми системами огромные массы сыпучего материала и противодействует развитию эрозионных процессов. Пройдя несколько сукцессионных стадий, лес превращается в луг. Этому способствует антропогенное воздействие на лесной массив. Оценка антропогенного воздействия на ландшафты выявила неблагоприятную ситуацию, которая проявляется, прежде всего, в загрязнении отходами хозяйственной деятельности людей. Массовое загрязнение реки послужило основной причиной потери ее рыбопродуктивности.

\section{ЗАКЛЮЧЕНИЕ}

Определены основные гидрологические и гидрометрические характеристики реки Малка. Исследован химический состав аллювиальных отло- жений на территории исследуемого участка реки, в грунте обнаружено содержание оксидов железа, титана и алюминия. Исследован химический состав и качество воды реки. Установлено, что речная вода соответствует третьему классу качества - умеренно загрязненная. При изучении геокомплексов поймы реки Малка выявлена повышенная динамичность геосистемы в связи с антропогенным воздействием, приводящим к возникновению модифицированных природных комплексов в ландшафте.

\section{СПИСОК ЛИТЕРАТУРЫ}

1. Водная среда: комплексный подход к изучению, охране и использованию. Петрозаводск, Карельский научный центр РАН, 2008. 155 с.

2. Муравьев А. Г. Руководство по определению показателей качества воды полевыми методами. СПб., «Крисмас+», 2009. 220 с.

3. Разумов В. В. [и др.] Переувлажнение и подтопление земель в регионах России. Москва, Почвенный институт им. В.В. Докучаева, 2018. 279 с.

4. Шамарина М.А. Формирование русловых форм рельефа в долине реки Малка в районе города Прохладного // Сборник статей XIII большого географического фестиваля. Санкт-Петербург, 2017, с. 64-67.

5. F. Richard Hauer, Harvey Locke, Victoria J. Dreitz, Mark Hebblewhite, Winsor H. Lowe, Clint C. Muhlfeld, Cara R. Nelson, Michael F. Proctor and Stewart B. Rood Gravel-bed river floodplains are the ecological nexus of glaciated mountain landscapes // Science Advances, 2, 2016. DOI: $10.1126 /$ sciadv. 1600026

Конфликт интересов: Авторы декларируют отсутствие явных и потенциальных конфликтов интересов, связанных с публикацией настоящей статьи.

Поступила в редакичию 07.04.2020 Принята к публикацчии 26.07.2020 


\title{
Geoecological Characteristics of the Malka River Sectionfrom the City of Prokhladnyto the Mouth
}

\author{
S. I. Shagin, M. A. Shamarina $\bowtie$, N. V. Tatarenko \\ Kabardino-Balkarian State University named after H. M. Berbekova, \\ Russian Federation \\ (173, Chernyshevsky st., Nalchik, 360004)
}

\begin{abstract}
The purpose is to study the variety of manifestations of channel and floodplain processes in the Malka River delta and assess their impact on the ecosystem, based on the analysis of data from open sources and our own observations, compile a comprehensive characteristic of the Malka River, compose its hydrochemical characteristics and describe the ion-salt composition, study the modern ecological and the physical and geographical state of the ecosystem and the hydrochemical composition of the Malka River in the area of the city of Prokhladny. Methods: During the study, general geographic methods were used, as well as generally accepted geobotanical and soil methods. Field hydrometric work included: measurement of width, depth, current speed, river slope. Results: Field hydrometric work was carried out. The main hydrological and hydrometric characteristics of the river in the study area have been determined. The chemical composition of alluvial deposits on the territory of the investigated section of the river was investigated. Found the content of oxides of iron, titanium and aluminum in the soil. The chemical composition and quality of water in the investigated section of the Malka River was investigated. It was found that the analyzed water corresponds to the third quality class - moderately polluted. Conclusions: In the period from 2015 to 2019, the following was studied: the physical and geographical state of the section of the Malka River from the city of Prokhladny to the mouth; the state of the ecosystem; processes of changes in the content of water-soluble salts in soils under the influence of natural and anthropogenic factors. Based on the analysis of the available literature data and our own observations, it has been established that the formation of channel relief forms occurs slowly, under the influence of many factors, the most significant of which are changes in climate, soil and the evolution of the river itself.
\end{abstract}

Key words: hydrological regime, morphometric indicators, ecosystem, floodplain landscapes, chemical composition.

For citation: Shagin S. I., Shamarina M. A., Tatarenko N. V. Geoecological characteristics of the Malka river section from the city of Prokhladny to the mouth. Vestnik Voronezskogo gosudarstvennogo universiteta. Geografia geoekologia, 2020, No. 3, pp. 72-77. (In Russ.) DOI: https://doi.org/10.17308/geo.2020.3/3026

\section{REFERENCES}

1. Vodnaya sreda: kompleksnyy podkhod k izucheniyu, okhrane i ispol'zovaniyu [Aquatic environment: an integrated approach to the study, protection and use]. Petrozavodsk, Karel'skiy nauchnyy tsentr RAN Publ., 2008. 155 p. (In Russ.)

2. Murav'yev A.G. Rukovodstvo po opredeleniyu pokazateley kachestva vody polevymi metodami [Guidance for the determination of water quality indicators by field meth- ods]. St. Petersburg, Publ. "Krismast", 2009. 220 p. (In Russ.)

3. Razumov V.V. [et all.] Pereuvlazhneniye i podtopleniye zemel'v regionakh Rossii [Waterlogging and waterlogging in the regions of Russia]. Moscow, Pochvennyy institut im. V. V. Dokuchayeva Publ., 2018. 279 p. (In Russ.)

4. Shamarina M. A. [Formation of channel landforms in the valley of the Malka river near the city of Prokhladny]. Sbornik statey XIII bol'shogo geograficheskogo festi-

(c) Shagin S.I., Shamarina M. A., Tatarenko N. V., 2020

\ Marina A. Shamarina, e-mail: shamarinam@mail.ru

The content is available under Creative Commons Attribution 4.0 License. 
valya [Collection of articles of the XIII Great Geographical Festival]. St. Petersburg, 2017, pp. 64-67. (In Russ.)

5. F. Richard Khauer, Kharvi Lokk, Viktoriya Dzh. Dreyts, Mark Khebblvayt, Uinzor KH. Lou, Klint S. Myul'fel'd, Kara R. Nel'son, Maykl F. Proktor i Styuart B. Rud Poymy rek graviynogo rusla yavlyayutsya ekologicheskimi svyaz' lednikovykh gornykh landshaftov [Grav-

\section{Шагин Сергей Иванович}

доктор географических наук, начальник управления научных исследований и инновационной деятельности, профессор кафедры биологии, геоэкологии и молекулярно-генетических основ живых систем, Кабардино-Балкарский государственный университет им. Х. М. Бербекова, г. Нальчик, Российская Федерация, ORCID: https://orcid.org/0000-0002-1784-5742, e-mail:

per-kbsu@mail.ru

Шамарина Марина Анатольевна

заместитель заведующего музеем живой природы, Кабардино-Балкарский государственный университет им. Х. М. Бербекова, г. Нальчик, Российская Федерация, ORCID: https://orcid.org/0000-0002-3602-1677, e-mail: shamarinam@mail.ru

Татаренко Николай Викторович

старший преподаватель кафедры биологии, геоэкологии и молекулярно-генетических основ живых систем, Кабардино-Балкарский государственный университет им. Х.М. Бербекова, г. Нальчик, Российская Федерация, ORCID:https://orcid.org/0000-0002-4733-4126, e-mail: tatarenko.nic@yandex.ru el-bed river floodplains are the ecological nexus of glaciated mountain landscapes]. Science Advances, 2, 2016. DOI: 10.1126 / sciadv. 1600026

Conflict of interests: The authors declare no information of obvious and potential conflicts of interest related to the publication of this article.

Received: 07.04.2020

Accepted: 26.07.2020

Sergey I. Shagin

Dr. (Geogr.) Sci., the Head of the Department of Scientific Research and Innovation, Professor of the Department of Biology, Geoecology and Molecular Genetic Foundations of Living Systems, Kabardino-Balkarian State University named after H.M. Berbekov, Nalchik, Russian Federation, ORCID: https://orcid.org/0000-0002-1784-5742, e-mail:

per-kbsu@mail.ru

Marina A. Shamarina

Deputy Head of the Museum of Wildlife of KabardinoBalkarian State University named after H.M. Berbekov, Nalchik, Russian Federation, ORCID:

https://orcid.org/0000-0002-3602-1677, e-mail: shamarinam@mail.ru

Nikolay V. Tatarenko

Senior Lecturer of the Department of Biology, Geoecology and Molecular Genetic Foundations of Living Systems, Kabardino-Balkarian State University named after H. M. Berbekov, Nalchik, Russian Federation, ORCID: https://orcid.org/0000-0002-4733-4126, e-mail: tatarenko.nic@yandex.ru 